Miami Nature Biotechnology Short Reports

TheScientificWorld (2001) 1 (S3), 117SR

ISSN 1532-2246; DOI 10.1100/tsw.2001.215

\title{
SEMISYNTHESIS OF PROTEIN VARIANTS USING INTEIN-MEDIATED PROTEIN LIGATION
}

\author{
Ulrich Arnold*, Matthew P. Hinderaker, and Ronald T. Raines
}

Department of Biochemistry, University of Wisconsin-Madison, 433 Babcock Drive, Madison, WI 53706, U.S.A.

*uarnold@biochem.wisc.edu

INTRODUCTION. The introduction of non-natural amino acid residues or modules into proteins enables the study of the significance of single amino acid residues or entire structural regions in the stability of the protein, its folding/unfolding behavior, or its biological function. Bovine pancreatic ribonuclease A (RNase A) is a small protein with a well-characterized structure and thoroughly studied stability and unfolding/folding behavior (1). More recently, RNase A also became a target of studies as a chemotherapeutic (2). We exploited the method of intein-mediated protein ligation (3) to introduce non-natural amino acid residues into the C-terminal part of RNase A and investigated the biochemical properties of the variants.

METHOD. Peptides containing either the wild-type RNase A sequence Cys95-Val124 or the same sequence with replacements for certain amino acid residues were synthesized by solidphase methods. Full-length RNase A or RNase A 1-94 and variants of these were produced as a fusion protein. The respective DNA sequence was inserted into the plasmids pTYB1 and pTXB1 to produce a fusion protein, which consists of RNase A (1-124 or 1-94) with an additional Met -1 , the intein, and a chitin-binding domain (4).

RESULTS. With pTYB1, purification of the fusion protein and thiol-facilitated formation of a thioester at the C-terminal Asn94 of the RNase A 1-94 fragment resulted in high amounts of cleavage product. However, only a little fraction contained the required thioester due to the slow intein cleavage and the fast thioester hydrolysis. Ligation of the intein cleavage product with the corresponding peptide yielded about $70 \mu \mathrm{g}$ of ligation product per liter of bacterial culture. An N94A RNase A 1-94 variant proved to result in considerable higher yields of thioester, enabling efficient ligation of the protein component with the peptide. Here, ligation yielded about $200 \mu \mathrm{g}$ of product per liter of bacterial culture. With pTXB1, the yields of fusion protein were substantially higher which allowed a formation of ligation product in reasonable amounts. 


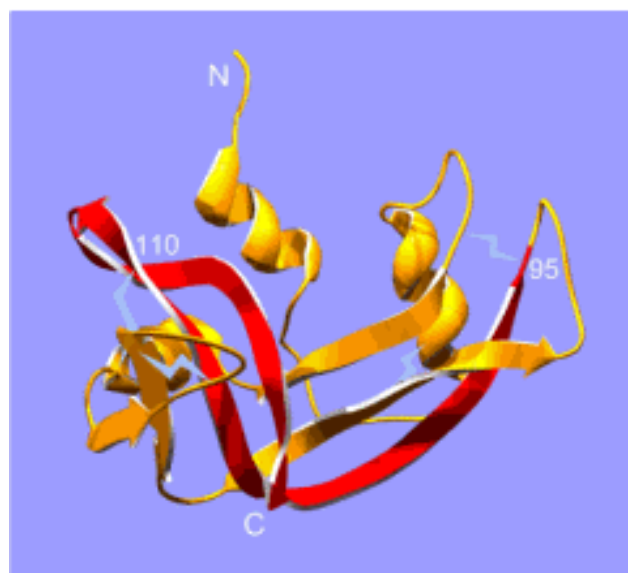

Fig. 1. RNase A construct: residues 1-94 were produced by use of the intein, residues 95-124 were synthesized by solid phase methods.

For comparison to semisynthetic RNase A variants with non-natural residues, wild-type RNase A 1-124 and N94A RNase A were produced by the intein method. Both intein cleavage products could be isolated at about $500 \mu \mathrm{g}$ per liter bacterial culture.

DISCUSSION. Our results show that semisynthesis of RNase A variants is possible by producing a protein fragment with a C-terminal thioester and subsequent ligation to a peptide with an N-terminal Cys residue. By this means, non-natural amino acid residues and even modules can be incorporated into protein structures. Variants containing the wild type sequence of RNase A in the peptide were identical with those RNase A variants produced as full-length proteins.

ACKNOWLEDGEMENT. This work was supported by the Arthur B. Michael Fund and grant GM44783 (NIH).

\section{REFERENCES.}

1. D'Alessio, G. and Riordan, J.F. (1997) Ribonucleases: Structures and Functions. Academic Press, New York

2. Leland, P.A., Schultz, L.W., Kim, B.-M., and Raines, R.T. (1998) Proc. Natl. Acad. Sci. U S A 95, 10407-10412

3. Evans, T.C. Jr., Benner, J., and Xu, M.Q. (1998) Protein Sci. 11, 2256-2264

4. New England Biolabs: IMPACT тм T7: One-step protein purification system 

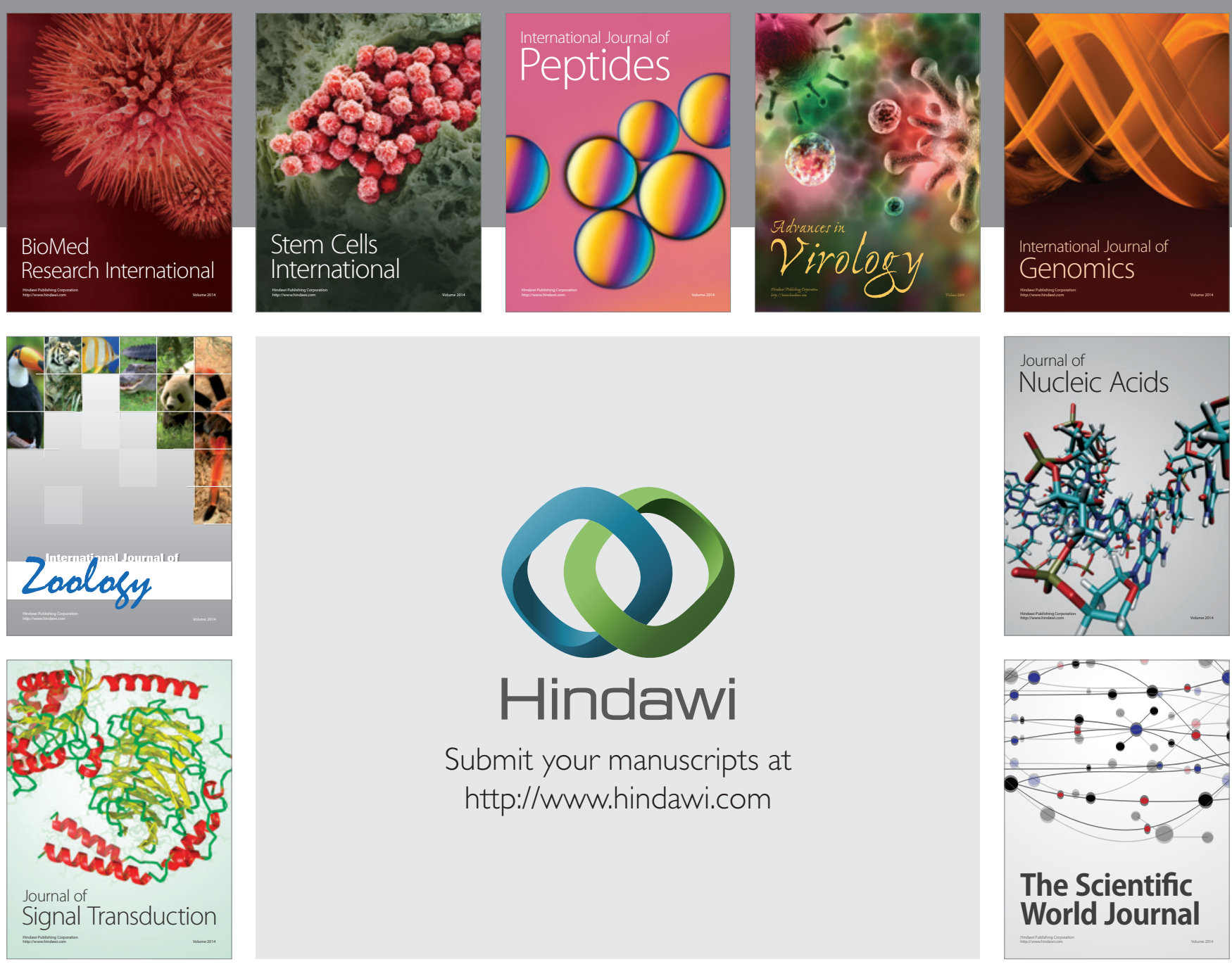

Submit your manuscripts at

http://www.hindawi.com
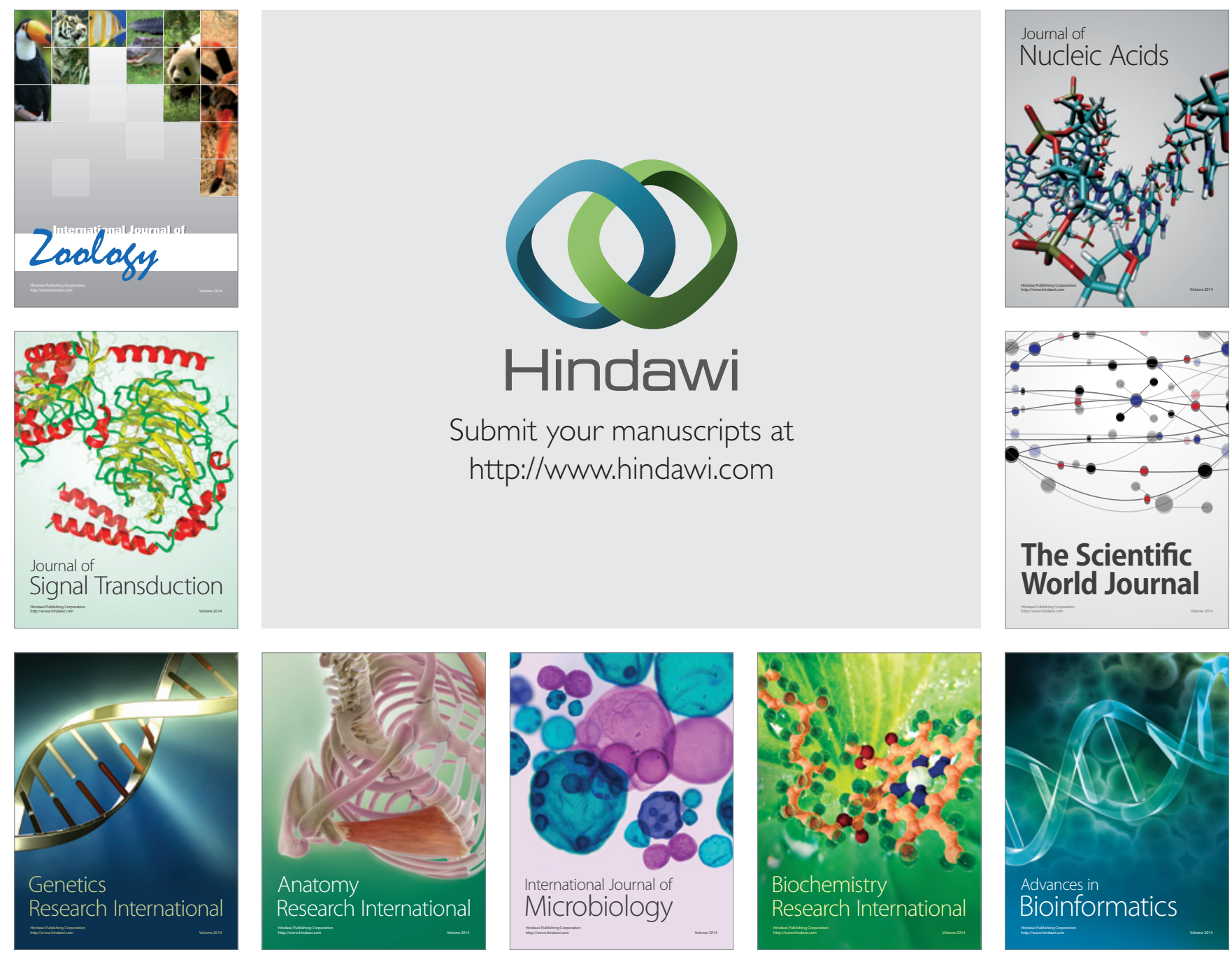

The Scientific World Journal
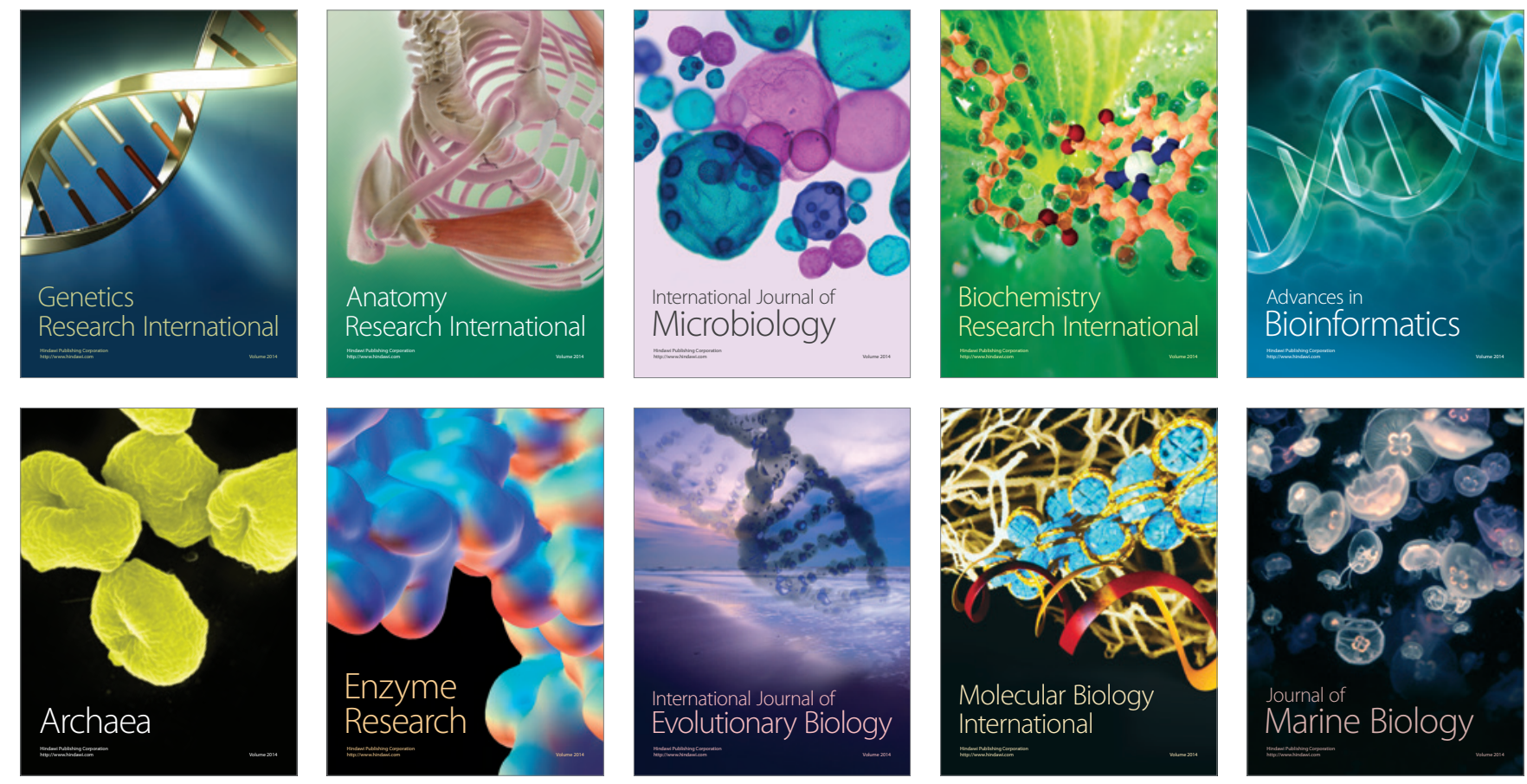